\title{
PROBLEMS OF EQUIVALENT LOAD AMPLITUDE IN FATIGUE LIFE CALCULATIONS
}

\author{
Bogdan Ligaj, Assoc. Prof. \\ Robert Soltysiak, Ph. D. \\ University of Technology and Science in Bydgoszcz, Poland
}

\begin{abstract}
This paper presents issues of fatigue life calculations in operational load conditions. The assumed runs were so processed as to get a set of sinusoidal cycles by using the following methods: full cycles counting method and rainflow counting method. On the basis of such sets of cycles of the varying parameters $S_{m i}$ and $S_{a i}$ were prepared block load spectra of equivalent amplitudes $S_{a z}$, obtained with the use of an original method of these authors, in which two-parameter fatigue characteristics were applied. The work resulted in comparison of fatigue life results for load spectra determined by using the assumed cycles counting methods and the assumed two-parameter fatigue characteristics: the model IM, model II, model III and model IV, respectively.
\end{abstract}

Keywords: operational load, equivalent load amplitude, two-parameter fatigue characteristics, fatigue life

\section{INTRODUCTION}

One of choice criteria for design features of machine parts are calculations in the area of material fatigue, dealing with range of fatigue life estimation in random load conditions. According to theory of stochastic processes, operational loads can be numbered among a group of either narrow or broad spectrum. Essential differences in fatigue life between the above mentioned loads deal with participation of cycles from a given range of values of the stress ratio $R$ and occurrence of cycles of large amplitude values (where the maximum amplitude $\mathrm{S}_{\mathrm{a}} \approx \mathrm{S}_{\max }$ ).

Fatigue life calculations for narrow spectrum loads are executed with the use of block load spectra (the spectra 1D) prepared on the basis of sets of cycles determined by means of one of the cycles counting methods: peak counting method, simple-range counting method, full cycles counting method, range-pair counting method and rainflow counting method. In [2] it was stated that choice of a cycles counting method for loads of the type does not significantly impair results of fatigue life calculations carried out with application of the fatigue characteristics $\mathrm{N}\left(\mathrm{S}_{\mathrm{a}}\right)$ (the characteristics $1 \mathrm{D}$ ).

In the case of broad spectrum loads, execution of fatigue calculations is based on load spectra which describe variability of the cycle parameters $\mathrm{S}_{\mathrm{mi}}$ and $\mathrm{S}_{\mathrm{ai}}$, exemplified by correlation tables expressed in $\mathrm{S}_{\mathrm{a}}-\mathrm{S}_{\mathrm{m}}$ or $\mathrm{S}_{\min }-\mathrm{S}_{\text {smax }}$ reference system (the spectra 2D). To apply spectra of the type is necessary as in the load occur cycles of stress ratio from the range $-\infty<\mathrm{R}<1$ and they impact fatigue life [4]. Choice of a cycles counting method is an important element of preparation of the load spectra 2D. Out of the known metods [2, 3] , the peak counting method is not advised for preparation of broad spectrum loads because it leads to the most unfavourable load conditions which make calculated fatigue life underestimated in comparison to experimental results. Other, above mentioned cycles counting methods are considered advisable for preparation of loads of the type. In fatigue life calculations the two-parameter fatigue characteristics $\mathrm{N}\left(\mathrm{S}_{\mathrm{a}}, \mathrm{S}_{\mathrm{m}}\right)$ are used, that allows to take into account influence of cycles of a given value of the stress ratio $\mathrm{R}$ on fatigue life.

This work is aimed at comparison of results of fatigue life calculation obtained for the load spectra prepared with the use of the selected cycles counting methods as well as the twoparameter fatigue characteristics. The calculations have been carried out by means of the equivalent load spectra of a block form, produced on the basis of the two-parameter fatigue characteristics described in the subject-matter literature as: the model IM, model II, model III and model IV.

This work contains characteristics of operational loads which make it possible to assess load spectrum breadth as well as to conduct counting the cycles by means of the following methods: the full cycles counting method (FCM) and the rainflow counting method (RFM) $[2,3]$. The produced load spectra $2 \mathrm{D}$ have been converted into block spectra $1 \mathrm{D}$ on the basis of which fatigue life has been determined. Results of the calculations have been subjected to a comparative analysis allowing to formulate final conclusions.

\section{OPERATIONAL LOAD}

In Fig. 1 are presented runs of stress changes in a structural element, which were recorded in operational load conditions. Because they are intended for application to fatigue life calculations they are given in the relative form $S_{i} / S_{\max }$ where 
$\mathrm{S}_{\max }$ stands for maximum value of stress change occurring in a load run.

A cursory analysis of the assumed runs reveals significant differences concerning frequency of load changes as well as occurrence of cycles with large amplitude values. An analysis of static and dynamic load components has been conducted on the basis of statistical parameters, i.e. mean and variance. Their values are presented in Tab. 1 . For the assumed runs the mean value is close to zero (Tab. 1, col. 2), however variance values show differences between runs. It implies a different form of loads in the range of amplitudes of cycles covered by their content.

(a)

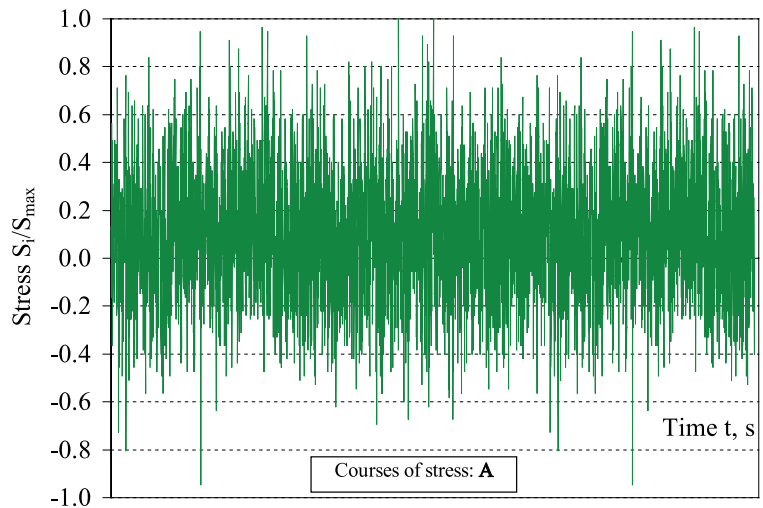

(b)

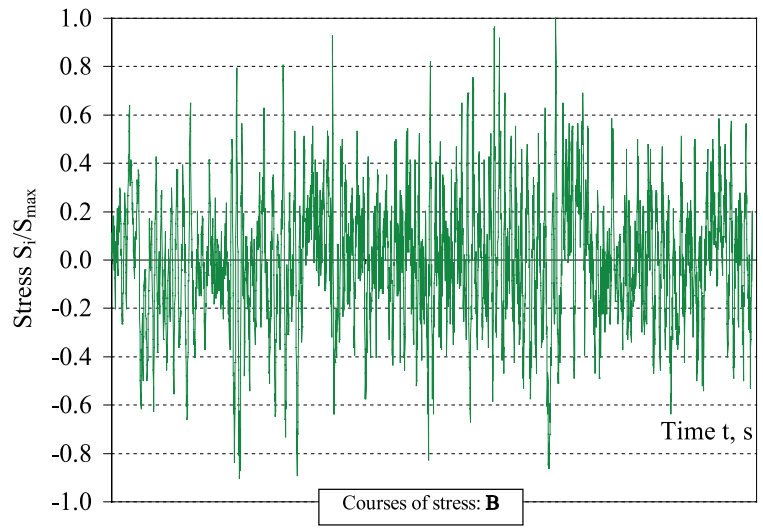

Fig. 1. Fragments of runs (courses) of stress changes in the form of the relative values $S_{i} / S_{\max }$

Tab. 1. Values of the selected statistical parameters of the load $S_{i} / S_{\max }$

\begin{tabular}{|l|l|l|l|l|}
\hline \multirow{2}{*}{ Load run } & \multicolumn{4}{|c|}{ Statistical parameter } \\
\cline { 2 - 5 } & Mean & Variance & Skewness & Kurtosis \\
\hline 1 & 2 & 3 & 4 & 5 \\
\hline A & -0.0026 & 0.1400 & 0.0600 & -0.7406 \\
\hline B & 0.0160 & 0.0780 & -0.0748 & 0.2775 \\
\hline
\end{tabular}

Values of skewness and kurtosis are also given in Tab. 1. Skewness represents a degree of asymmetry of a distribution around its mean, and kurtosis determines a relative peak or flat form of a distribution in relation to normal distribution [1]. Therefore on the basis of the presented results (Tab.1, col. 4 and 5) as well as of an analysis of values in load runs (not given in this paper due to its restricted volume) it can be assumed that the distribution of values in the runs is close to normal. (a)

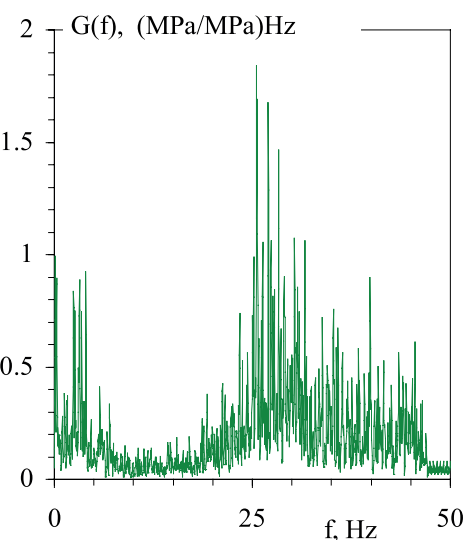

(b)

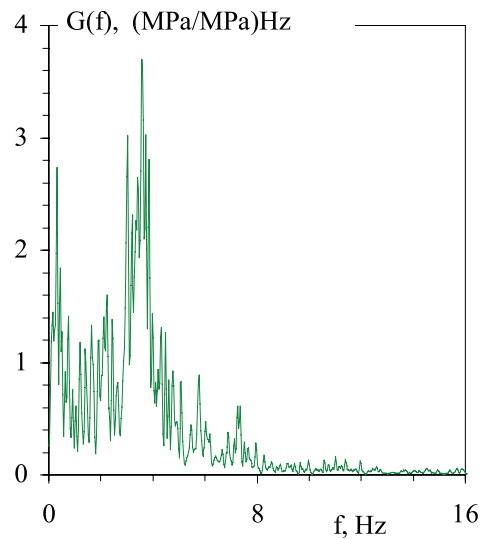

Fig 2. Spectral power density for runs of $S_{i} / S_{\max }$ loads: $a$ - the run $A, b$ - the run $B$

A complex frequency structure of the analyzed load runs is illustrated by spectral power density function diagrams shown in Fig. 2. The range of significant frequencies for the run $A$ is $0<\mathrm{f}<47 \mathrm{~Hz}$, and for the run $\mathrm{B}-0<\mathrm{f}<12 \mathrm{~Hz}$. The observed differences in frequency structure and values of variance (being a measure of stress amplitudes) of load runs are connected with excitation factors which occur during operation. The analyzed load runs can be numbered among the group of broad- spectrum loads, that is implied by a characteristic form of the diagrams of spectral power density functions.

Another way of assessing the load spectrum breadth which does not require using a complex statistical analysis, is to determine value of the factor I expressed as follows:

$$
\mathrm{I}=\frac{\mathrm{N}_{\mathrm{i}}}{\mathrm{N}_{\mathrm{e}}}
$$

In Eq. (1) $\mathrm{Ni}$ is number of intersections of mean value level by increasing and decreasing half-cycles, and $\mathrm{Ne}$ is number of local extrema occurring in a run ( sum of minimum and maximum values ). The method is described in [5]. The determined values of $\mathrm{I}$ - factor are the following : for the run $\mathrm{A}-\mathrm{IA}=0.8411$, for the run $\mathrm{B}-\mathrm{IB}=0.3828$. On this basis the assumed load runs can be numbered among the group of broad-spectrum loads. The conclusion is in line with that resulting from statistical analysis. 


\section{BLOCK SPECTRUM OF LOADS}

Load runs were subjected to a procedure of determining the set of sinusoidal cycles.

The following cycles counting methods were assumed: full cycles counting method (FCM) and rainflow counting method (RFM) [2, 3].

The determined data sets contained sinusoidal cycles of the parameters $S_{a i} / S_{\max }$ and $S_{\operatorname{mi}} / S_{\max }$ from the range of the stress ratio $-\infty<\mathrm{R}<1.0$, that is characteristic for broad-spectrum loads. Based on the collected data, were prepared the cycles sets having $S_{m}=0$ and the equivalent amplitude $S_{a z}$ determined on the basis of two-parameter fatigue characteristics.

\section{METHOD FOR DETERMINING THE EQUIVALENT LOAD SPECTRA}

For determining the equivalent amplitude $S_{a z}$ the two-parameter fatigue characteristics (TFC) is used. For purposes of this work the two-parameter fatigue characteristics called:

the model IM (Fig.3a) [6], model II (Fig.3b) [6], model III (Fig.3c) [6] and model IV (Fig.3d) [6] were used. The method for determining the equivalent amplitude $S_{a z i}$ consists in determining a line of constant fatigue life ( $\mathrm{N}=$ const) for an arbitrary sinusoidal load cycle of the parameters $S_{m i}$ and $S_{a i}$ (the point $G$ in Fig.3), by using the two-parameter fatigue characteristics. The point $\mathrm{G}$ is interpolated to the point of intersection of the constant fatigue life line and the axis of ordinates of the TFC coordinate frame ( the point C) for which the mean stress value is equal to $S_{m}=0$. In this way the equivalent load cycle of the stress ratio $\mathrm{R}=-1$ was determined. It should be stressed that all load cycles located on the constant fatigue life line ( $\mathrm{N}=$ const) have the same equivalent amplitude Saz i regardless of in which TFC zone they are located.

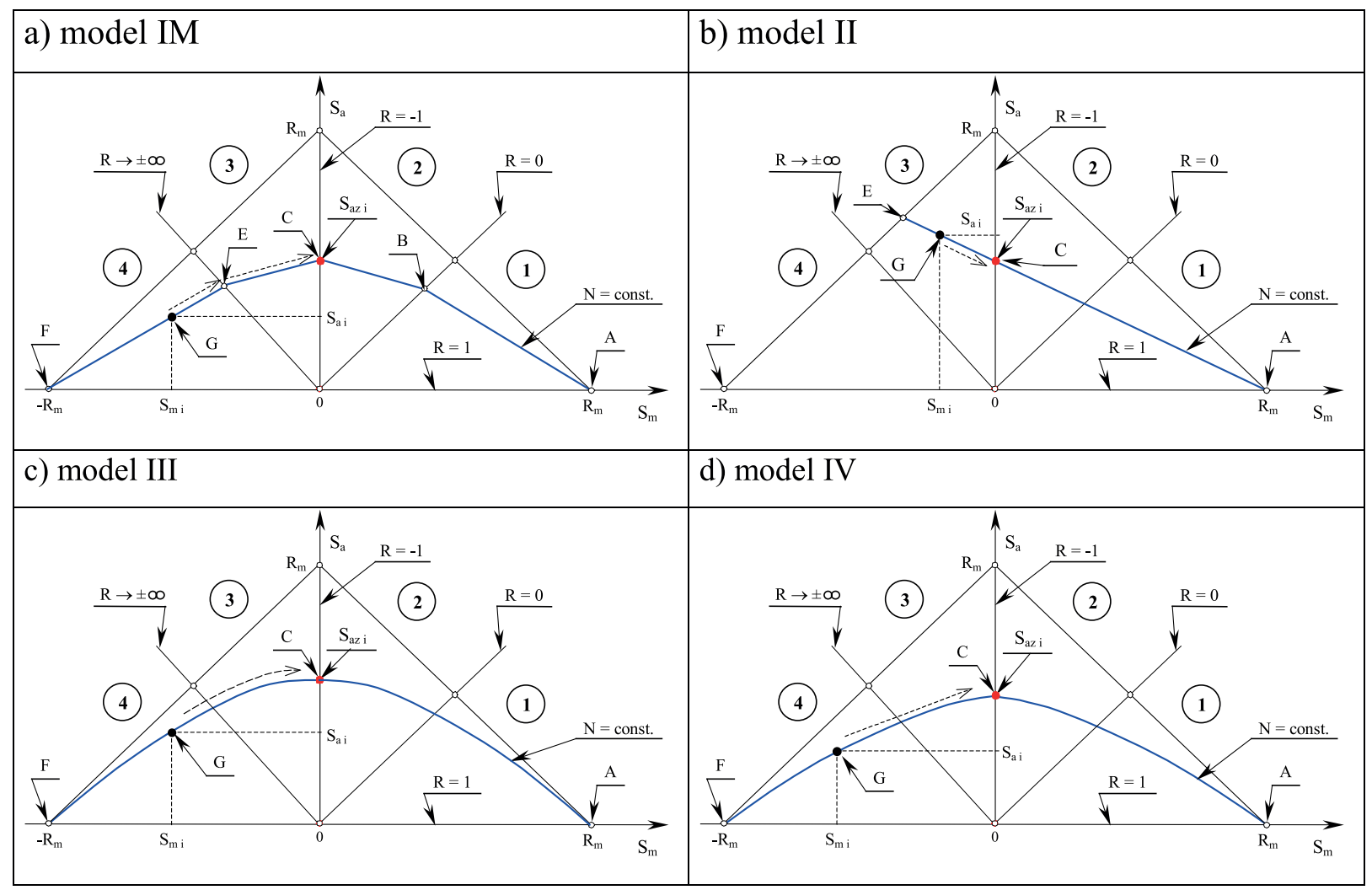

Fig. 3. Schematic presentation of the mathematical models of TFC characteristics : a - model IM [6], a - model II [4], c-model III [4], d-model IV [4]

The model IM of the two-parameter fatigue characteristics (Fig.3a) is a modified model I [6] which represents a generalization of the Serensen's limiting stress diagram over the HCF and LCF ranges. In Fig 3. figures 1 through 4 stand for the variability ranges of the cycle stress ratio R. Form of the expression describing the constant fatigue life lines ( $\mathrm{N}=$ const) for particular TFC zones is as follows :

- zone 1

$$
\mathrm{N}=\mathrm{N}_{0}\left[\frac{\mathrm{S}_{\mathrm{f}(-1)} \cdot\left(\mathrm{R}_{\mathrm{m}}+\mathrm{S}_{\mathrm{a}(\mathrm{R})}^{(\mathrm{T})}-\mathrm{S}_{\mathrm{m}(\mathrm{R})}^{(\mathrm{T})}\right)}{\mathrm{S}_{\mathrm{a}(\mathrm{R})}^{(\mathrm{T})} \cdot \mathrm{R}_{\mathrm{m}} \cdot\left(1+\psi_{\mathrm{N}}\right)}\right]^{\mathrm{m}_{(-1)}} \text { for } 0<\mathrm{R}<1
$$

- zone 2

$$
N=\frac{N_{0} \cdot\left(S_{f(-1)}\right)^{m_{(-1)}}}{\left(S_{a(R)}^{(T)}+\psi_{N} \cdot S_{m(R)}^{(T)}\right)^{m_{(-1)}}}
$$
for $-1 \leq \mathrm{R} \leq 0$

- zone 3

$$
\mathrm{N}=\frac{\mathrm{N}_{0} \cdot\left(\mathrm{S}_{\mathrm{f}(-1)}\right)^{\mathrm{m}_{(-1)}}}{\left(\mathrm{S}_{\mathrm{a}(\mathrm{R})}^{(\mathrm{T})}-\psi_{\mathrm{N}} \cdot \mathrm{S}_{\mathrm{m}(\mathrm{R})}^{(\mathrm{T})}\right)^{\mathrm{m}_{(-1)}}}
$$


- zone 4

$$
\mathrm{N}=\mathrm{N}_{0}\left[\frac{\mathrm{S}_{\mathrm{f}(-1)} \cdot\left(\mathrm{R}_{\mathrm{m}}+\mathrm{S}_{\mathrm{a}(\mathrm{R})}^{(\mathrm{T})}+\mathrm{S}_{\mathrm{m}(\mathrm{R})}^{(\mathrm{T})}\right)}{\mathrm{S}_{\mathrm{a}(\mathrm{R})}^{(\mathrm{T})} \cdot \mathrm{R}_{\mathrm{m}} \cdot\left(1+\psi_{\mathrm{N}}\right)}\right]^{\mathrm{m}_{(-1)}}
$$

for $1<\mathrm{R}<+\infty$

The model II [4] is a generalization of the Goodman's formula over the limiting fatigue life ranges LCF and HCF. The constant fatigue life line ACE corresponds to a constant fatigue life for sinusoidal load of varying parameters $\mathrm{Sm} i$ and $\mathrm{Sa}$ i contained in the range $-\infty<\mathrm{R}<1,0$. The mathematical model of the characteristics is of the following form:

$$
\mathrm{N}=\mathrm{N}_{0}\left[\frac{\mathrm{S}_{\mathrm{f}(-1)} \cdot\left(\mathrm{R}_{\mathrm{m}}+\mathrm{S}_{\mathrm{a}(\mathrm{R})}^{(\mathrm{T})}+\mathrm{S}_{\mathrm{m}(\mathrm{R})}^{(\mathrm{T})}\right)}{\mathrm{S}_{\mathrm{a}(\mathrm{R})}^{(\mathrm{T})} \cdot \mathrm{R}_{\mathrm{m}} \cdot\left(1+\psi_{\mathrm{N}}\right)}\right]^{\mathrm{m}_{(-1)}}
$$

The Gerber's mathematical model was applied to forming the model III [4] of the two-parameter fatigue characteristics. The constant fatigue life line $(\mathrm{N}=$ const) is described by the following formula:

$$
\mathrm{N}=\mathrm{N}_{0}\left[\frac{\mathrm{S}_{\mathrm{f}(-1)}}{\mathrm{S}_{\mathrm{a}(\mathrm{R})}^{(\mathrm{T})}}\left(1-\left(\frac{\mathrm{S}_{\mathrm{m}(\mathrm{R})}^{(\mathrm{T})}}{\mathrm{R}_{\mathrm{m}}}\right)^{2}\right)\right]^{\mathrm{m}_{(-1)}}
$$

The model IV [4] was formed on the basis of ellipse equation describing the limiting stress line. The mathematical model of the characteristics is of the following form:

$$
\mathrm{N}=\mathrm{N}_{0}\left[\frac{\mathrm{S}_{\mathrm{f}(-1)}}{\mathrm{S}_{\mathrm{a}(\mathrm{R})}^{(\mathrm{T})}} \sqrt[1-\left(\frac{\mathrm{S}_{\mathrm{m}(\mathrm{R})}^{(\mathrm{T})}}{\mathrm{R}_{\mathrm{m}}}\right)^{2}]{]^{\mathrm{m}_{(-1)}}}\right.
$$

\section{BLOCK LOAD SPECTRA}

By applying the above described method for determining the equivalent amplitudes $S_{a z}$, block load spectra were determined for the assumed operational runs. It was based on sets of sinusoidal cycles produced by means of the assumed cycles counting methods. The applied two-parameter fatigue life characteristics were made for $\mathrm{C} 45$ steel with the following properties [7] in loading conditions:

$$
\begin{gathered}
\text { - static ones: } \mathrm{E}=211029 \mathrm{MPa}, \mathrm{R}_{\mathrm{m}}=\mathrm{S}_{\mathrm{y}}=682 \mathrm{MPa}, \mathrm{R}_{\mathrm{e}}=\mathrm{S}_{\mathrm{u}}=458 \mathrm{MPa} \text {, } \\
\text { - cycling ones : } \mathrm{m}_{(-1)}=9.80, \mathrm{C}_{(-1)}=1.054 \cdot 10^{29}, \\
\mathrm{~S}_{\mathrm{f}(-1)}=223.5 \mathrm{MPa}, \mathrm{k}=0.1378, \psi_{\mathrm{N}}=\mathrm{N}^{-\mathrm{k}} .
\end{gathered}
$$

The block load spectra used in fatigue life calculations were determined separately for each of the assumed values of $\mathrm{S}_{\max }$ contained within the variability range: $200 \mathrm{MPa} \leq \mathrm{S}_{\max } \leq 600$ $\mathrm{MPa}$. Because of a limiting volume of this paper only the example block load spectra for $\mathrm{S}_{\max }=400 \mathrm{MPa}$ are presented for the stress change runs marked: A (Fig.4) and B (Fig.5). In the below attached tables are additionally given values characteristic for the block load spectra: in tab. 2 - spectrum filling factor $\zeta$, in Tab. 3 - values of maximum equivalent amplitudes $\mathrm{S}$

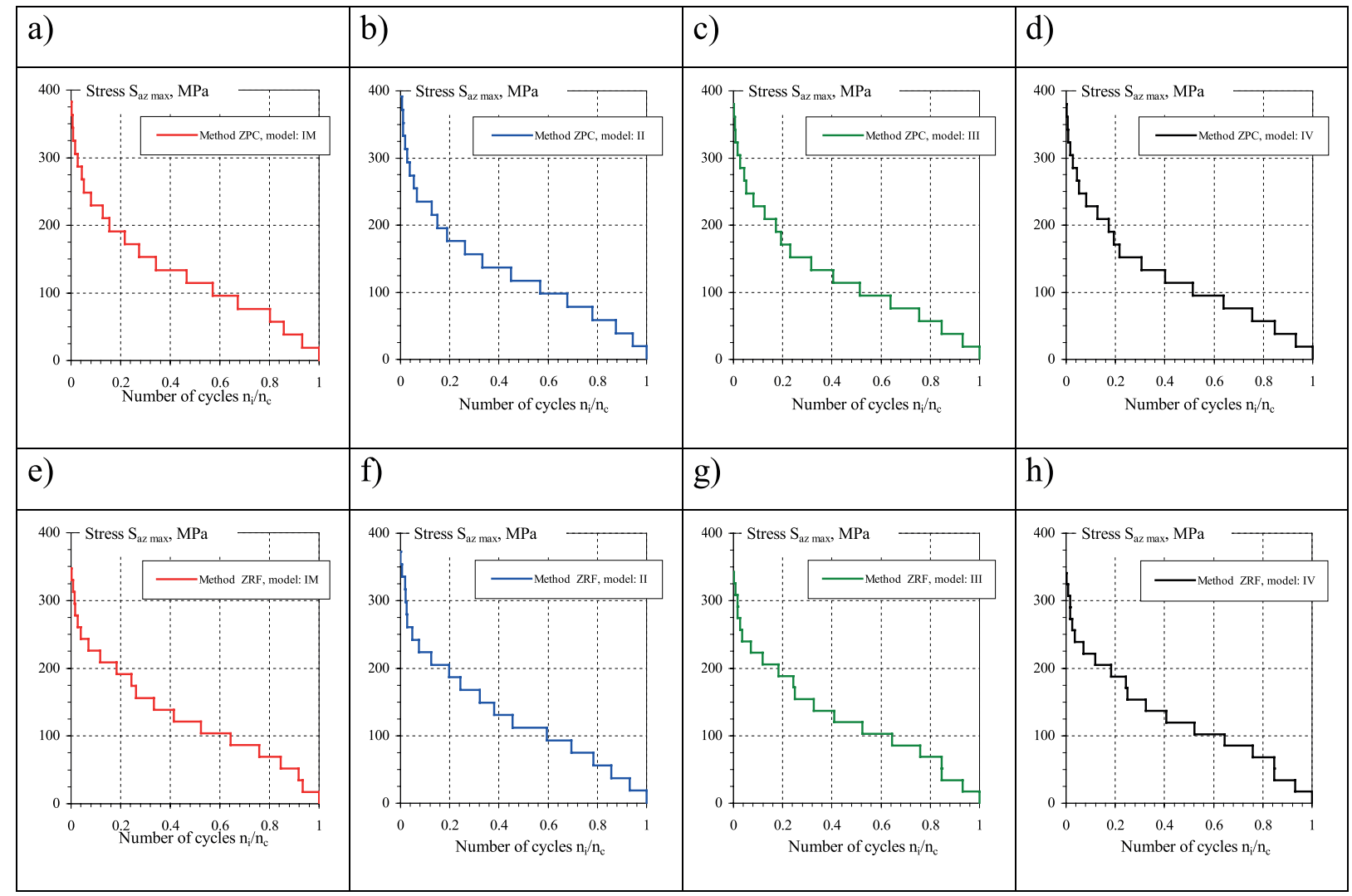

Fig. 4. Block load spectra for $S_{\max }=400 \mathrm{MPa}$, determined for the run A by using the following cycles counting methods: a-d - full cycles counting method (FCM), e-h - rainflow counting method (RFM) 


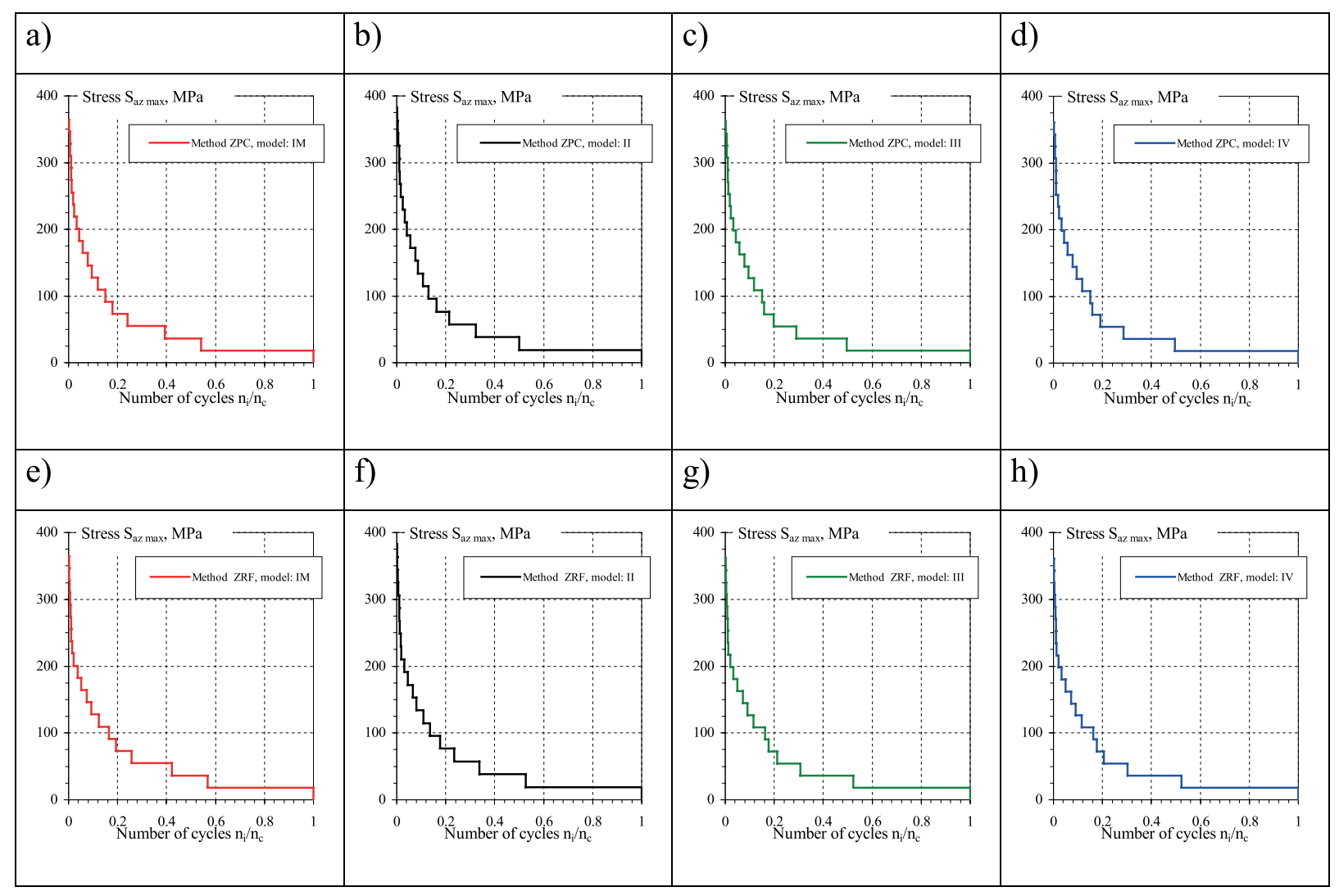

Fig. 5. Block load spectra for $S_{\max }=400 \mathrm{MPa}$, determined for the run B by using the following cycles counting methods: a-d - full cycles counting method (FCM), e- $h$ - rainflow counting method (RFM)

Tab.2. Values of the spectrum filling factor $\zeta$

\begin{tabular}{|c|c|c|c|c|c|}
\hline \multirow{2}{*}{$\begin{array}{l}\text { Cycles counting } \\
\text { method }\end{array}$} & \multirow{2}{*}{ Load run } & \multicolumn{4}{|c|}{ Two-parameter characteristics } \\
\hline & & Model IM & Model II & Model III & Model IV \\
\hline \begin{tabular}{|l|l|}
1 \\
\end{tabular} & 2 & 3 & 4 & 5 & 6 \\
\hline \multirow{2}{*}{$\begin{array}{l}\text { Full cycles counting } \\
\text { method }(\mathrm{FCM})\end{array}$} & Run A & 0.3327 & 0.3292 & 0.3181 & 0.3167 \\
\hline & Run B & \begin{tabular}{|l|l|}
0.1509 \\
\end{tabular} & 0.1407 & 0.1401 & 0.1396 \\
\hline \multirow{2}{*}{$\begin{array}{l}\text { Rainflow counting } \\
\text { method (RFM) }\end{array}$} & Run A & 0.3680 & 0.3404 & 0.3630 & 0.3625 \\
\hline & Run B & 0.1531 & 0.1413 & 0.1411 & 0.1406 \\
\hline
\end{tabular}

Tab. 3. Values of the maximum equivalent amplitude $S_{\text {az } \max }$

\begin{tabular}{|c|c|c|c|c|c|}
\hline \multirow{2}{*}{$\begin{array}{l}\text { Cycles counting } \\
\text { method }\end{array}$} & \multirow{2}{*}{ Load run } & \multicolumn{4}{|c|}{ Two=-parameter characteristics } \\
\hline & & Model IM & Model II & Model III & Model IV \\
\hline 1 & 2 & 3 & 4 & 5 & 6 \\
\hline \multirow{2}{*}{$\begin{array}{l}\text { Full cycles counting } \\
\text { method }(\mathrm{FCM})\end{array}$} & Run A & 382.4 & 391.5 & 380.3 & 380.2 \\
\hline & Run B & 364.9 & 382.4 & 361.3 & 360.6 \\
\hline \multirow{2}{*}{$\begin{array}{l}\text { Rainflow counting } \\
\text { method (RFM) }\end{array}$} & Run A & 347.3 & 372.8 & 342.7 & 341.3 \\
\hline & Run B & 364.9 & 382.4 & 361.3 & 360.6 \\
\hline
\end{tabular}

From the analysis of the parameters contained in Tab. 2 and 3 it may be concluded that as a result of cycles counting by means of the methods : full cycles counting method (FCM) and rainflow counting method (RFM), were determined the data sets differing to each other by share of cycles (especially those of large values of $S_{a i} / S_{\text {max }}$ ) in spectrum for particular loads. This is confirmed by values of spectrum filling factor $\zeta$ (Tab.2) as well as values of maximum equivalent amplitude Saz max (Tab.3). In the case of the run A can be observed significant differences in load spectra (concerning both $\zeta$ and
$\mathrm{S}_{\mathrm{az} \max }$ values), resulting from the assumed cycles counting method and used TFC model. In the case of the run B the differences in load spectra concern first of all the used twoparameter fatigue characteristics, whereas the cycles counting method did not have any influence on values either of $\zeta$ or $\mathrm{S}_{\mathrm{az} \max }$.

\section{RESULTS OF CALCULATIONS}

The fatigue life calculations were conducted in stress mode by using Wöhler fatigue life diagram experimentally determined under load of $\mathrm{R}=-1$. Its equation is of the following form:

$$
\log \mathrm{S}_{\mathrm{a}}=-\frac{1}{9.80} \log \mathrm{N}+2.9611
$$

In the calculations the Palmgren-Miner's hypothesis on linear fatigue damage summation was used [8]; expressed as follows:

$$
\mathrm{D}=\sum_{\mathrm{i}=1}^{\mathrm{k}} \frac{\mathrm{n}_{\mathrm{i}}}{\mathrm{N}_{\mathrm{i}}}=1.0
$$

and, results of fatigue life were presented in the form of a number of used load blocks, calculated from the equation:

$$
\lambda=\frac{1}{\mathrm{D}}
$$


The calculations performed with the use of the equivalent load spectra made it possible to produce fatigue life diagrams in the coordinate frame $S_{\text {max }}=f(\lambda)$, where $S_{\text {max }}$ is maximum stress value in load run. In Fig. 6 results of the calculations are presented in the form of fatigue life diagrams for the runs $\mathrm{A}$ and $\mathrm{B}$.

Their preliminary assessment (Fig. 6) shows that the smallest fatigue life has been obtained for the load spectra determined by using the PCM method for the run A, that

a)

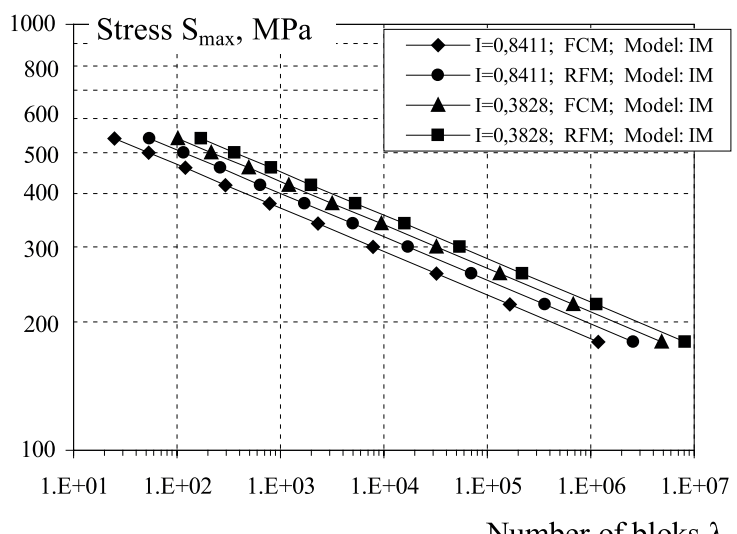

c)

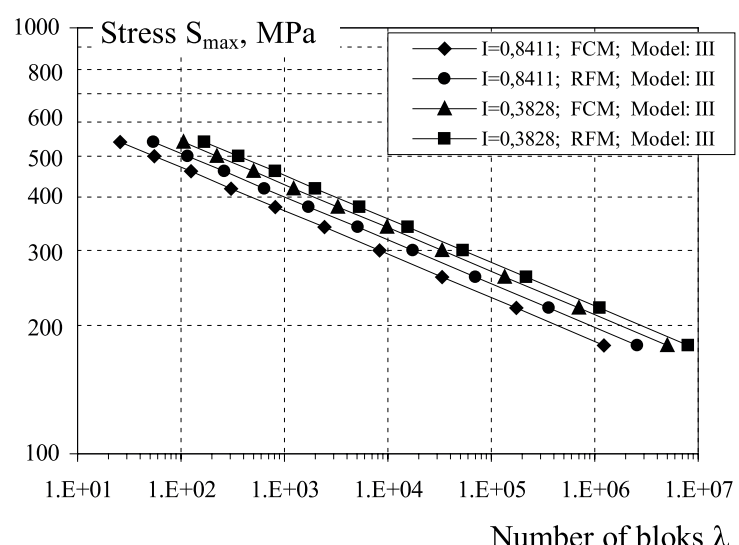

results from the greater value of the equivalent amplitude $\mathrm{S}_{\mathrm{az} \max }$. The largest fatigue life has been reached for the run $\mathrm{B}$ and the RFM cycles counting method. Comparison of the results in the context of application of two-parameter fatigue characteristics to determining the equivalent load spectrum, shows that the smallest fatigue life was obtained for TFC model II, and the fatigue life values for the models: IM, III and IV are close to each other.

b)

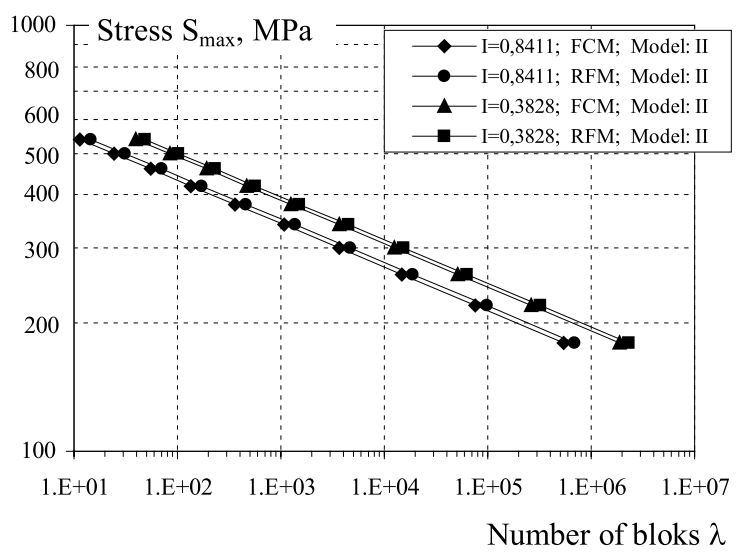

d)

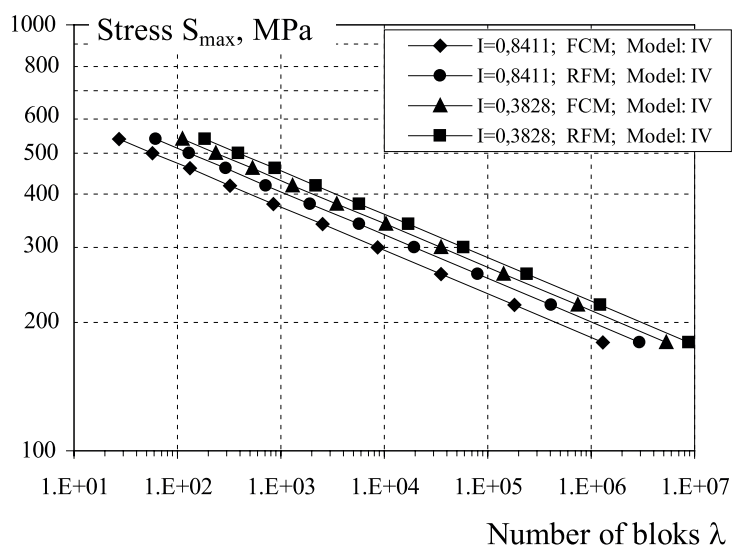

Fig. 6. Results of fatigue life calculations for load spectra determined by using two-parameter fatigue characteristics: $a$ - model IM, $b$ - model II, $c$ - model III, $d$ - model IV

\section{ANALYSIS OF RESULTS OF THE RESEARCH}

Differences between calculation results obtained for the assumed load runs as well as the applied method of cycles counting were determined on the basis of an analysis of value of the difference in relative fatigue lives $\delta_{(\mathrm{N})}$, calculated from the equation:

$$
\delta_{(\mathrm{N})}=\frac{\mathrm{N}_{(\mathrm{x})}-\mathrm{N}_{(\mathrm{R}=-1)}}{\mathrm{N}_{(\mathrm{R}=-1)}}
$$

Value of the fatigue life $\mathrm{N}(\mathrm{x})$ is that expressed by number of cycles determined from calculations, whereas $\mathrm{N}(\mathrm{R}=-1)$ is that read from Wöhler diagram for value of the stress amplitude $\mathrm{Sa}(\mathrm{Sa}=\mathrm{Smax})$. The results read from Wöhler diagram served as the reference point in the analysis. Values of relative differences between the analyzed characteristics are presented graphically in Fig. 7. 


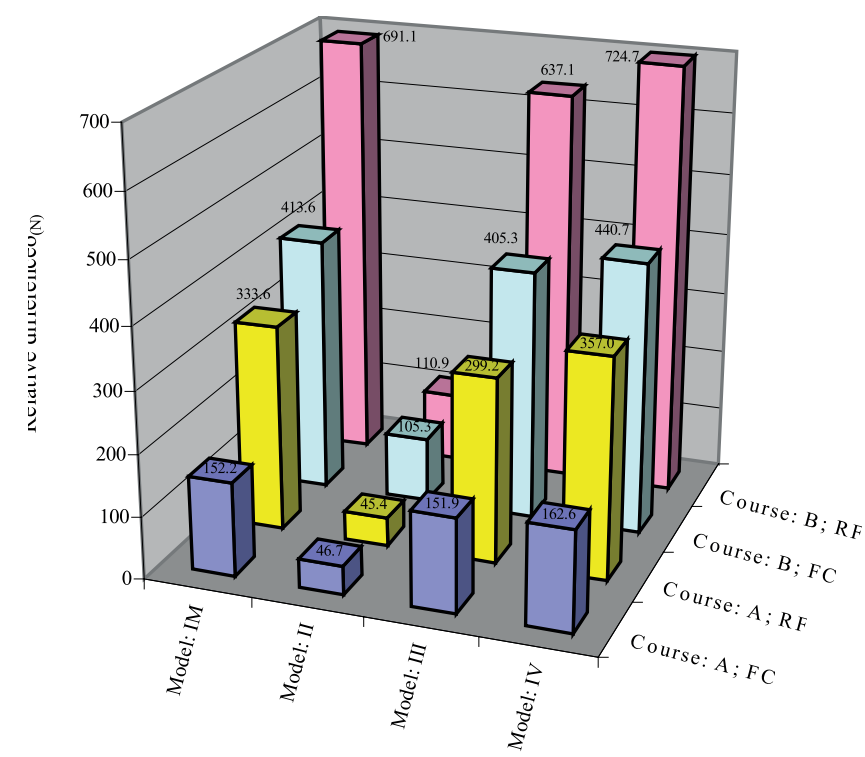

Fig.7. Values of relative differences in fatigue life for the assumed operational loads subjected to cycles counting by means of the selected methods as well as two-parameter models of fatigue characteristics

A detailed analysis indicates that the hardest load conditions were obtained for the run A subjected to processing by means of the full cycles counting method (FCM). Values of the relative differences in fatigue life are contained within the range from $\delta_{(\mathrm{N}) \mathrm{II}}=46.7$ to $\delta_{(\mathrm{N}) \mathrm{IV}}=162.6$. The largest fatigue life was reached for the model IV of two-parameter fatigue characteristics and all the block load spectra. In the case of the models: IM, III and IV similar results of fatigue life were obtained for particular equivalent load spectra. It results from rather small differences in values of the spectrum filling factor $\zeta$ and equivalent amplitude $S_{\text {az max }}$. The smallest value of fatigue life was obtained for the model II of TFC characteristics as a consequence of occurrence, in the equivalent load spectrum , of cycles of significantly higher amplitude values in relation to the spectrum determined for the models: IM, III and IV.

The presented results of calculation of the relative differences $\delta_{(\mathrm{N})}$ make it also possible to determine relations between the assumed cycles counting methods. For the load run A the difference in fatigue life results, obtained during calculations performed according to the models: IM, III and IV, shows increase of fatigue life by about $100 \%$ for equivalent load spectra determined by using the rainflow counting method (RFM) in relation to the full cycles counting method (FCM). In the case of the load run B an increase in fatigue life also occurs but it reaches only about $40 \%$.

\section{SUMMARY}

The way of preparing the equivalent load spectra , combined with application of the selected cycles counting methods (full cycles counting method and rainflow counting method) and two-parameter fatigue characteristics, revealed differences in results of fatigue life calculations. It may be stated that the calculation results are influenced by the assumed cycles counting method and TFC model. In view of the close fatigue life results obtained for the models: IM, III and IV it is possible to use one of them for preparing the equivalent load spectra to be applied to calculations for a given kind of structural materials [4].

The presented set of fatigue life calculation methods makes it possible to take into account mean value of load cycles (having stress ratio values different from $\mathrm{R}=-1$ ) in calculations where Wöhler fatigue life diagram determined for $R=-1$, is used. It is of a great importance in the case of estimating fatigue life of machinery elements working in conditions of broad - spectrum operational loads.

Choice of a model for determining the equivalent load spectra is associated with cyclic properties of a considered material. For example, the cyclic properties of S355J0 steel can be described by means of the model: IM, III and IV of two-parameter fatigue characteristics [4]. On this basis it is advisable to apply the above mentioned models of fatigue characteristics to calculations conducted in the preliminary stage of structural design process.

\section{ABBREVIATIONS:}

FCM - full cycles counting method,

PCM - peak counting method,

RCM - simple-range counting method,

RFM - rainflow counting method,

RPM - range-pair counting method,

TFC - two-parameter fatigue characteristics,

$\mathrm{HCF}$ - range of high cycle fatigue,

LCF - range of low cycle fatigue.

\section{BIBLIOGRAPHY}

1. Bendat J.S., Pierdol A.G., Methods of analysis and measurement of random signals (in Polish), PWN, Warszawa, 1976.

2. Kocańda S., Szala J., Fundamentals of fatigue calculations (in Polish), PWN, Warszawa, 1997.

3. Norma ASTM, Standard practices for cycle counting in fatigue analysis, ASTM Designation: E 1049-85 (Reapproved 1990).

4. Ligaj B., Szala G., Experimental verification of twoparametric models of fatigue characteristics by using the tests of S355J0 steel as an example, Polish Maritime Research, No.1 (2010), pp. 39-50.

5. Szala J., Loads and fatigue life of machine elements (in Polish), University of Technology and Agriculture, Bydgoszcz 1989.

6. Szala G., Ligaj B., Description of cyclic properties of steel in variability conditions of mean values and amplitudes of loading cycles, Materials Science Forum, Fatigue Failure and Fracture Mechanics, Vol. 726, 2012, pp. 69-76. 
7. Szala G., Theoretical and experimental analysis of twoparametric fatigue life characteristics of structural steels (in Polish), 1st part of the monograph titled: Twoparametric fatigue life characteristics of structural steels and their experimental verification, Publishing House of Operation Technology Institute, State Research Institute, Radom, 2011.

8. Szala G., Comments on linear summation hypothesis of fatigue failures, Polish Maritime Research, No.3 (2014), pp. 77-85.
CONTACT WITH AUTHOR

$$
\text { Bogdan Ligaj }
$$

bogdan.ligaj@utp.edu.pl

Robert Sołtysiak

robert.soltysiak@utp.edu.pl

University of Technology and Science in Bydgoszcz Faculty of Mechanical Engineering

Department of Mechanics and Machine Design 7 Prof. S. Kaliski Street

85-796 Bydgoszcz

Poland

phone:

(+48) 523408253

(+48) 523408278 